\title{
Complete cardiac and bronchial avulsion in a dog: Post-mortem computed tomography and forensic necropsy analysis
}

\author{
Ana Carolina Brandão de Campos Fonseca Pinto ${ }^{\mathrm{a}}$, Mara Rita Rodrigues Massad ${ }^{\mathrm{b}}$, Laila \\ Massad Ribas ${ }^{\mathrm{b}, *}$, Carina Outi Baroni ${ }^{\mathrm{a}}$, Tália Missen Tremori ${ }^{\mathrm{b}}$, Sérvio Túlio Jacinto Reis ${ }^{\mathrm{b}}$, Noeme \\ Sousa Rocha ${ }^{\mathrm{b}}$ \\ a Surgery Department, School of Veterinary Medicine and Animal Science, University of São Paulo, São Paulo, Brazil \\ b Department of Veterinary Clinical Sciences, School of Veterinary Medicine and Animal Science, São Paulo State University, Botucatu, Brazil
}

\section{A R T I C L E I N F O}

\section{Keywords:}

Forensic science

Forensic pathology

Forensic radiology

Post-mortem diagnosis

Aorta

Cardiac trauma

\begin{abstract}
A B S T R A C T
The aim of this case report was to describe non-contrast tomography findings of a cardiovascular trauma followed by a forensic necropsy in a dog. A female dog was struck by a vehicle, suffered a sudden death and was sent to a veterinary hospital. PMCT images were acquired on a 16-slice multidetector scanner and the forensic necropsy was performed afterwards. Thoracic images revealed aorta avulsion, heart dislocation, complete right bronchial rupture, pneumothorax, pleural effusion, subcutaneous emphysema, multiple rib and spine processes fractures, and a diaphragmatic rupture. Abdominal images showed free abdominal fluid, and laceration of the abdominal muscles leading to eventration of small bowel. Forensic necropsy findings corroborated the hypothesis of cardiac and bronchial avulsion. Even though no contrast media was administered in this case, it was possible to establish the cause of death based solely on the PMCT images. Further studies in this field should be conducted to evaluate the capabilities of PMCT in improving post-mortem diagnosis or even replacing it when necessary.
\end{abstract}

\section{Introduction}

Cardiac and bronchial avulsions are very rare conditions in animals and humans. They are mainly related to blunt chest trauma [1-4]. Vehicle accidents are one of the main causes of death in dogs, with the thorax being the first region of injuries caused by this sort of trauma $[5,6]$. In humans, about one third of blunt traumatic fatalities is associated with thoracic aortic injuries, increasing the risk of injuries to the thorax and the abdominal cavity [7].

Post-mortem Computed Tomography (PMCT) has a high sensitivity for identifying trauma injuries, being a valuable additional technique to forensic science [8]. However, there are still few descriptions of postmortem images in veterinary medicine, especially obtained by PMCT [8-14]. The aim of this case report was to describe PMCT findings of a cardiovascular trauma followed by a forensic necropsy in a dog.

\section{Case}

A female dog died after being struck by a vehicle and was sent to a private veterinary hospital. Since it was not equipped with a computed tomography imaging system, the cadaver was transported to a school of veterinary medicine, where a PMCT was performed.

PMCT images were acquired, with the body placed in dorsal recumbency, using a 16-slice multidetector scanner MX800 (Philips, Cleveland, OH, USA). The scan parameters were $120 \mathrm{kVp}, 350 \mathrm{mAs}$, slice thickness ranged from $1 \mathrm{~mm}$ (head and parenchyma) to $2 \mathrm{~mm}$ (abdomen and mediastinum), and slice interval ranged from $0.5 \mathrm{~mm}$ (head and parenchyma) to $1 \mathrm{~mm}$ (abdomen and mediastinum). A veterinary radiologist analyzed the images and a veterinary pathologist performed the forensic necropsy in the private hospital.

Thoracic images revealed aorta avulsion, heart dislocation, complete right bronchial rupture, pneumothorax, pleural effusion, subcutaneous emphysema, and diaphragmatic rupture (Fig. 1). Multiple rib and spine processes fractures were observed in the CT images, especially with the 3D volume reconstruction (Fig. 2). Abdominal images showed free abdominal fluid, and laceration of the abdominal muscles leading to eventration of small bowel (Fig. 3).

All necropsy findings were consistent with the PMCT images. The heart was dislocated to the right side of the thorax due to a complete avulsion of all great cardiac vessels (Fig. 4). Both the radiologist and the pathologist agreed that hemorrhagic shock was the cause of death of this dog.

\footnotetext{
* Corresponding author.

E-mail address: lailamassad@gmail.com (L.M. Ribas).
} 

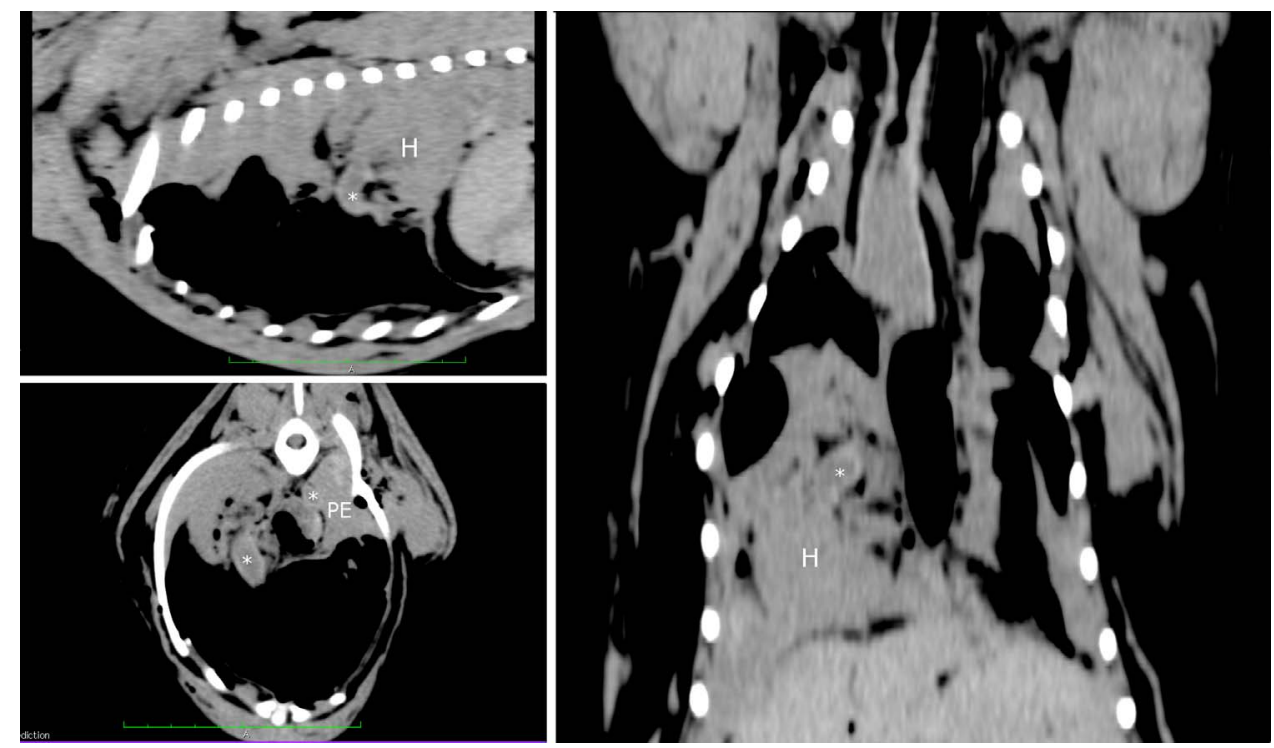

Fig. 1. PMCT MPR images show complete aortic rupture $\left(^{*}\right)$ with dorsocaudal heart displacement $(\mathrm{H})$ and pleural effusion (PE).

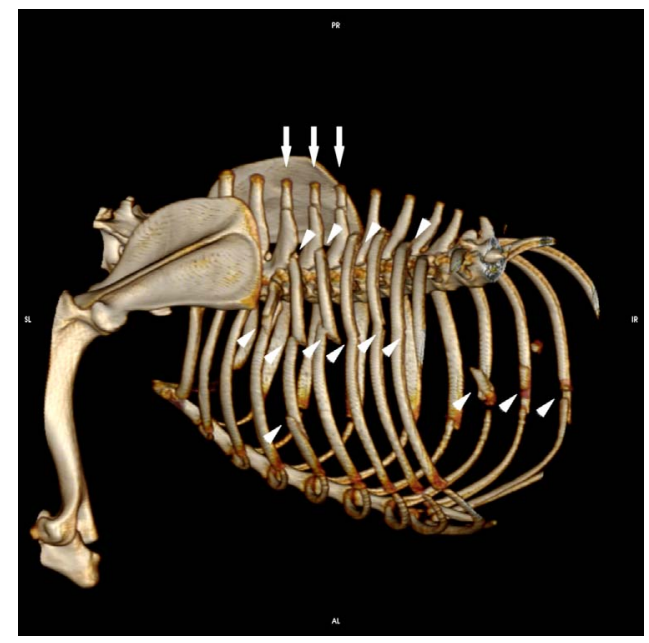

Fig. 2. Volume-rendered 3D image of the thorax showing multiple bones fractures of spinous processes (arrows) and ribs (arrowheads).

\section{Discussion}

Forensic necropsy findings corroborated the hypothesis of cardiac and bronchial avulsion. Even though no contrast was administered in this case, it was possible to visualize complete aortic and bronchial

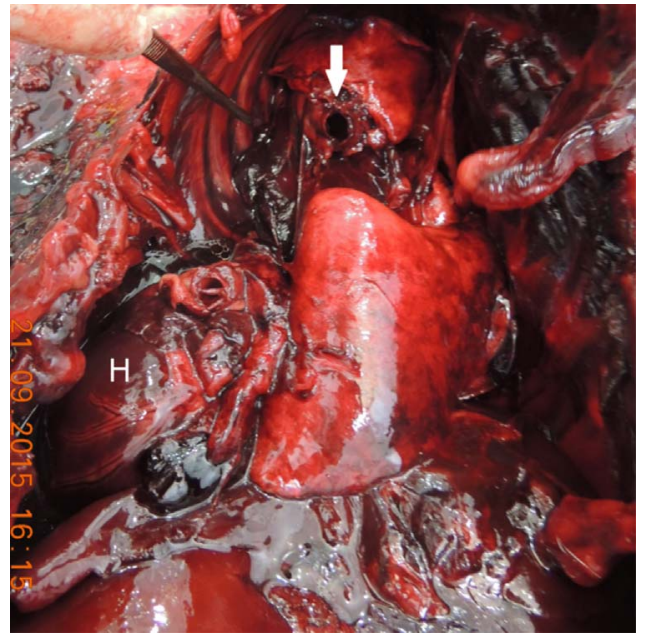

Fig. 4. Necropsy image of the thorax in correspondence to the Fig. 1. Note the heart displacement $(\mathrm{H})$, the aorta rupture (arrowhead) and the bronchial avulsion (arrow).

rupture, enough information to conclude that the animal had a sudden death by hemorrhage. In human forensic radiology, comparisons between PMCT or PMCTA (PMCT angiography) and conventional necropsy are well documented [15-18].

Computed tomography proved to be a very important technique to
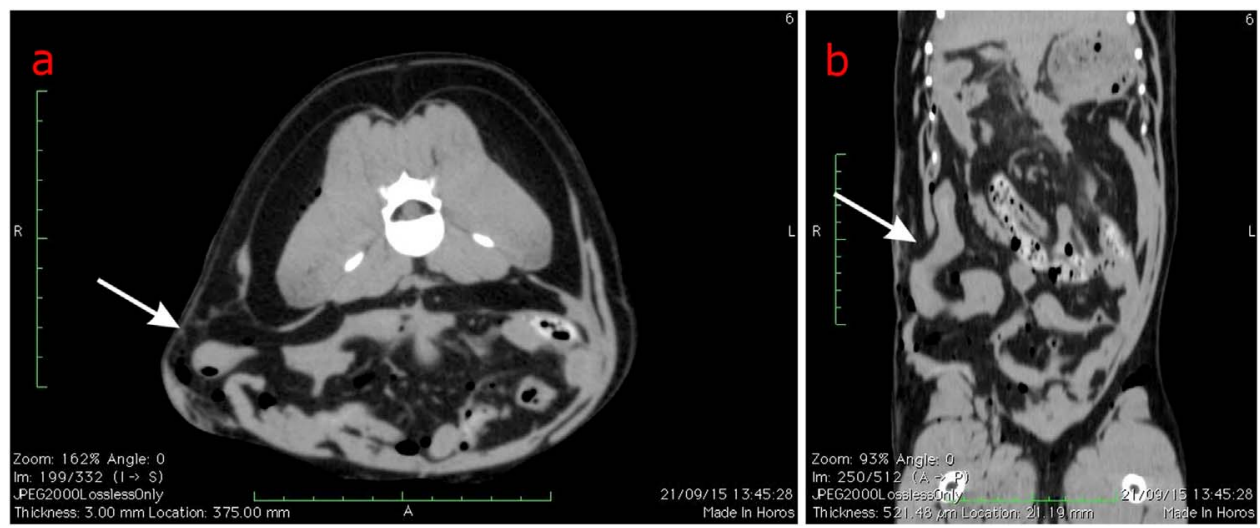

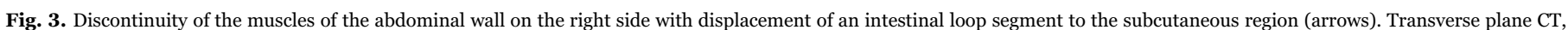
soft tissue window (a); dorsal plane CT, soft tissue window (b). 
assist forensic science, especially because small fractures and small amounts of gas in the vascular system or cavities are infrequently observed in conventional necropsy or even by using traditional radiography, whereas they are well documented in PMCT images $[19,20]$. Hence, it is a complementary tool, which should be more explored by veterinarians, mainly when a veterinary pathologist is not present to conduct the necropsy or even when there is a suspicion of zoonosis, considering the veterinary exposure to these kinds of diseases during conventional necropsy.

Although there are some reported cases of bronchial avulsion in veterinary medicine $[4,21]$, to the best of our knowledge, there is no cardiac avulsion case reported in animals. So, this is perhaps the first complete cardiac and bronchial avulsion case reported in a dog.

The analysis of veterinary CT images requires specific knowledge of the animal's anatomy and pathology from the observers, besides knowhow related to the interpretation of post-mortem images. Therefore, a new field of investigation is emerging in veterinary medicine, as it happened in human medicine.

Despite the lack of contrast media administration in this study, it was possible to establish the cause of death using PMCT images alone. Further studies in this field would be desirable to evaluate the capabilities of PMCT in improving necropsy in veterinary medicine or even replacing it when necessary.

\section{Declaration of interest}

The authors report no conflicts of interest. The authors alone are responsible for the content and writing of the paper.

\section{Acknowlegments}

This work was supported by "Coordenação de Aperfeiçoamento de Pessoal de Nível Superior” - CAPES, Edital Ciências Forenses 25/ 2014. Process number 99999.000199/2016-08.

\section{References}

[1] R. Karmy-Jones, D.E. Wood, Traumatic injury to the trachea and bronchus, Thorac. Surg. Clin. 17 (1) (2007) 35-46.

[2] C. Natale, H. De Lesquen, F. Beranger, B. Prunet, P.M. Bonnet, J.P. Avaro, Blunt bronchial injuries: a challenging issue, Inj. Extra 45 (3) (2004) 22-24.

[3] F. Navid, T.G. Gleason, Great vessel and cardiac trauma: diagnostic and management strategies, Semin. Thorac. Cardiovasc. Surg. 20 (1) (2008) 31-38.

[4] R.N. White, M.R. Oakley, Left principal bronchus rupture in a cat, J. Small Anim.
Pract. 42 (10) (2001) 495-498.

[5] R.A. Fighera, T.M. Silva, J.C. Brum, G.D. Kommers, D.L. Graça, L.F. Irigoyen, C.S.L. Barros, Pathological aspects of 155 fatal cases of dogs victimized by motor vehicles accidents, Ciência Rural 38 (5) (2008) 1375-1380.

[6] A.C. Stoian, E. Ciobotaru, C.M. Constantinescu, G. Dinescu, G. Predoi, Lesions induced by motor vehicle accidents in dogs and cats, J. Comp. Pathol. 52 (1) (2015) 71.

[7] P.G. Teixeira, K. Inaba, G. Barmparas, C. Georgiou, C. Toms, T.T. Noguchi, C. Rogers, L. Sathyavagiswaran, D. Demetriades, Blunt thoracic aortic injuries: an autopsy study, J. Trauma-Inj. Infect. Crit. Care 70 (1) (2011) 197-202.

[8] A. Christe, P. Flach, S. Ross, D. Spendlove, S. Bolliger, P. Vock, M.J. Thali, Clinical radiology and post-mortem imaging (Virtopsy) are not the same: specific and unspecific postmortem signs, Leg. Med. 12 (5) (2010) 215-222.

[9] S. Franckenberg, F. Kernb, M. Vogt, M.J. Thali, P.M. Flach, Fatal gunshot to a fox: the Virtopsy approach in a forensic veterinary case, J. Forensic Radiol. Imaging 3 (1) (2015) 72-75.

[10] H.G. Heng, W.T. Teoh, A.R. Sheikh-Omar, Postmortem abdominal radiographic findings in feline cadavers, Vet. Radiol. Ultrasound 49 (1) (2008) 26-29.

[11] F.C. Hostettler, D.J. Wiener, M.M. Welle, H. Posthaus, U. Geissbühler, Post mortem computed tomography and core needle biopsy in comparison to autopsy in eleven Bernese mountain dogs with histiocytic sarcoma, BMC Vet. Res. 2 (2015) 229.

[12] K.J. Lee, M. Sasaki, A. Miyauchi, M. Kishimoto, J. Shimizu, T. Iwasaki, Virtopsy in a red kangaroo with oral osteomyelitis, J. Zoo Wildlife Med. 42 (1) (2011) $128-130$.

[13] R.M. Martinez, U. Hetzel, M.J. Thali, W. Schweitzer, Cat CAT-scan: postmortem imaging and autopsy of two cats, J. Forensic Radiol. Imaging 3 (1) (2015) 80-86.

[14] M.J. Thali, B.P. Kneubuehl, S.A. Bolliger, A. Christe, U. Koenigsdorfer, C. Ozdoba, E. Spielvogel, R. Dirnhofer, Forensic veterinary radiology: ballistic-radiological 3D computertomographic reconstruction of an illegal lynx shooting in Switzerland, Forensic Sci. Int. 171 (1) (2007) 63-66.

[15] B.A. Hoey, J. Cipolla, M.D. Grossman, N. McQuay, P.R. Shukla, S.P. Stawicki, C. Stehly, W.S. Hoff, Postmortem computed tomography, "CATopsy", predicts cause of death in trauma patients, J. Trauma-Inj. Infect. Crit. Care 63 (5) (2007) 979-985.

[16] I. Le Blanc-Louvry, S. Thureau, C. Duval, F. Papin-Lefebvre, J. Thiebot, J.N. Dacher, C. Gricourt, E. Touré, B. Proust, Postmortem computed tomography compared to forensic autopsy findings: a French experience, Eur. Radiol. 23 (7) (2013) 1829-1835.

[17] F. Makhlouf, V. Scolan, G. Ferretti, C. Stahl, F. Paysant, Gunshot fatalities: correlation between postmortem multi-slice computed tomography and autopsy findings: a 30-month retrospective study, Leg. Med. 15 (3) (2013) 145-148.

[18] I.S. Roberts, R.E. Benamore, E.W. Benbow, S.H. Lee, J.N. Harris, A. Jackson, S. Mallett, T. Patankar, C. Peebles, C. Roobottom, Z.C. Traill, Post-mortem imaging as an alternative to autopsy in the diagnosis of adult deaths: a validation study, Lancet 379 (9811) (2012) 136-142.

[19] A. Panda, A. Kumar, S. Gamanagatti, B. Mishra, Virtopsy computed tomography in trauma: normal postmortem changes and pathologic spectrum of findings, Curr. Probl. Diagn. Radiol. 44 (5) (2015) 391-406.

[20] S.G. Ross, S.A. Bolliger, G. Ampanozi, L. Oesterhelweg, M.J. Thali, P.M. Flach, Postmortem CT angiography: capabilities and limitations in traumatic and natural causes of death, Radiographics 34 (3) (2014) 830-846.

[21] P.A. Schmierer, A. Schwarz, D.A. Bass, S.C. Knell, Novel avulsion pattern of the left principal bronchus with involvement of the carina and caudal thoracic trachea in a cat, J. Feline Med. Surg. 16 (8) (2014) 695-698. 